\title{
ANALISIS OPTIMASI PENGGUNAAN FAKTOR PRODUKSI KOPI BUBUK PADA AGROINDUSTRI XYZ DI KOTA JAMBI
}

\author{
Riri Oktari Ulma*, Dewi Sri Nurchaini, Yusma Damayanti \\ Fakultas Pertanian Universitas Jambi \\ Jl. Kemajuan, Mendalo Darat, Jambi Luar Kota, Muaro Jambi, Jambi 36361 \\ *Corresponding author: ryryady_ulma@yahoo.com
}

\begin{abstract}
This research was aimed to determine the use of production factors optimal coffee beans and labor in the coffee powder agroindustry. The results showed that each additional raw material for coffee beans by $10 \%$ will increase the production of powder coffee by $4.09 \%$, while the addition of labor will increase the production of powder coffee by $4.14 \%$. The use of coffee bean raw material production factors can be added up to an optimal limit of $28,876.35 \mathrm{~kg} / q u a r t e r$ or there is an increase of $23.68 \%$ in the actual use. In one month the optimal limit is the amount of raw material used to be $9,625.45 \mathrm{~kg}$ or $385.02 \mathrm{~kg}$ per day. The use of labor can be added up to an optimal limit of 114 working people (HOK) or an increase of $25.30 \%$ of the actual use of labor. Calculated in working hours, the optimal use of working hours is 17,100 working hours per quarter or 5,700 working hours per month. Within one workday the limit for the optimal use of work is 228 hours with the number of workers being \pm 38 people. The optimum amount of production is 27,354.32/quarter, an increase of $5,165.02 \mathrm{~kg}(23.28 \%)$ of actual production. The optimum profit increased by $R p$ $335,257,566.67$ or $23.68 \%$ of the actual profit.
\end{abstract}

Keywords: coffee agroindustry, profit, production factor, optimal

\begin{abstract}
Abstrak: Penelitian ini bertujuan untuk menganalisis tingkat optimasi/efisiensi ekonomi penggunaan faktor produksi biji kopi dan tenaga kerja pada agroindustri kopi bubuk dan melakukan pendekatan untuk menghitung jumlah optimal penggunaan faktor produksi biji kopi dan tenaga kerja yang optimal pada agroindustri kopi bubuk di kota Jambi. Hasil penelitian menunjukkan bahwa setiap penambahan bahan baku biji kopi sebesar 10\% maka akan meningkatkan produksi kopi bubuk sebesar 4,09\%, sedangkan penambahan tenaga kerja $10 \%$ akan meningkatkan produksi kopi bubuk sebesar 4,14\%.Penggunaan faktor produksi biji kopi per triwulan dapat ditambah hingga jumlah optimal menjadi sebesar $28.876,35 \mathrm{~kg} /$ triwulan atau terdapat kenaikan 23,68\% dari penggunaan aktual. Dalam satu bulan batas jumlah optimal jumlah bahan baku yang dipakai menjadi $9.625,45 \mathrm{~kg}$ atau $385,02 \mathrm{~kg}$ per hari.Penggunaan tenaga kerja dapat ditambah hingga batas optimal menjadi sebesar 114 hari orang kerja (HOK) atau terjadi penambahan $25,30 \%$ dari penggunaan tenaga kerja aktual. Dihitung dalam jam kerja maka jumlah optimal penggunaan jam kerja menjadi 17.100 jam kerja per triwulan atau 5.700 jam kerja per bulan. Dalam satu hari kerja jumlah penggunaan optimal kerja menjadi 228 jam dengan jumlah pekerja menjadi \pm 38 orang. Jumlah produksi optimum adalah27.354,32 kg/triwulan, meningkat sebesar 5.165,02 $\mathrm{kg}(23,28 \%)$ dari produksi aktual. Keuntungan optimum meningkat sebesar Rp 335.257.566,67 atau 23,68\% dari keuntungan aktual.
\end{abstract}

Kata Kunci: agroindustri kopi, keuntungan, faktor produksi, optimal 


\section{PENDAHULUAN}

Kopi merupakan suatu komoditas perkebunan yang memiliki pasaran cukup menjanjikan di pasar dunia. Oleh karena itu, pemerintah telah memberikan dukungannya terhadap komoditas kopi ini dengan cara meningkatkan ekspor ke negara lain. Pada saat ini, Indonesia menempati posisi ke-4 dengan volume ekspor kopi sebesar 5.977.000 ton, sedangkan posisi pertama ditempati oleh Brazil dengan volume ekspor kopi sebesar 36.420 .000 ton (International Coffee Organization, 2014). Selain meningkatkan ekspor, dukungan pemerintah terhadap pengembangan komoditas kopi adalah meningkatkan pembangunan dan pengembangan agroindustri kopi dalam negeri (Soekartawi, 2001). Agroindustri memiliki beberapa kontribusi terhadap pembangunan pertanian, yaitu meningkatkan kegiatan agribisnis, mampu menyerap tenaga kerja, mampu dalam mendorong tumbuhnya industri lain.

Kota Jambi merupakan bagian dari wilayah Provinsi Jambi yang memiliki potensi yang sangat besar dalam perkembangan industri pengolahan kopi. Salah satu agroindustri yang bergerak dalam bidang pengolahan kopi ini adalah PD XYZ yaitu agroindustri yang didirikan pada Tahun 2003 dan mengolah biji kopi menjadi kopi bubuk. Kopi bubuk instan sangat diminati oleh konsumen karena praktis (Mizfar dan Sinaga, 2015). Secara financial agroindustri kopi bubuk ini layak untuk diusahakan dan dikembangkan karena memberikan laba (keuntungan) bagi pengusaha tersebut (Supriyadi, 2017). Namun dilihat dari optimalitas dalam penggunaan faktor produksi belum diketahui. Hal ini perlu untuk diketahui karena produktivitas penggunaan faktor produksi bahan baku dan tenaga kerja tidak stabil atau berfluktuasi dari Tahun 2012 sampai dengan Tahun 2016. Sementara itu rasio harga produk dan faktor produksi pada agroindustri kopi bubuk PD XYZ terus mengalami penurunan. Pada Tahun 2012 rasio harga kopi bubuk dengan harga biji kopi sebagai bahan baku menunjukan angka tertinggi yaitu 2,196 kemudian terus menurun pada tahun 2016 menjadi 1,720. Ini artinya setiap setiap 1 rupiah harga kopi bubuk di Tahun 2012 adalah 2,196 kali dari harga bahan baku (bji kopi), dan pada tahun 2016 menurun menjadi 1,720 kali dari harga biji kopi. Rasio harga kopi bubuk dengan upah tenaga kerja pada tahun 2012 sebesar 0,046, kemudian pada tahun 2016 turun menjadi 0,034. Menurunnya rasio harga ini menunjukan semakin rendahnya nilai produk kopi bubuk dibandingkan nilai dari faktor produksi. Kenaikan biaya produksi bisa menjadi lebih besar dari pada penerimaan yang akan diterima agroindustri, yang pada akhirnya dapat mempengaruhi menurunnya keuntungan yang akan diterima

Tingkat harga yang berfluktuasi mempengaruhi efsiensi harga dari agroindustri kopi bubuk PD XYZ. Demikian juga dengan produktivitas faktor produksi yang tidak stabil akan mengganggu efisiensi teknik/fisik dalam penggunaan bahan baku dan tenaga kerja. Kedua efisiensi ini yaitu teknis dan harga merupakan kondisi yang mempengaruhi efisiensi ekonomis dalam penggunaan faktor produksi untuk mendapatkan produk yang optimal.

Menurut Soekertawi (1994) prinsip optimalisasi penggunaan faktor produksi adalah bagaimana menggunakan faktor produksi tersebut seefisien mungkin. Prinsip ini pada hakekatnya meliputi dua tujuan yaitu maksimisasi keuntungan ataukah minimisasi biaya. Dalam penelitian ini optimasi yang dimaksud adalah bagaimana upaya penggunaan faktor produksi pada agroindustri kopi bubuk bisa optimal sehinggga keuntungan yang diterima agroindustri menjadi maksimum. Doll dan Orazem (1978), menyatakan bahwa, dalam terminologi ekonomi jumlah faktor produksi/ input yang menguntungkan disebut juga dengan jumlah optimum. Masalah ekonomi produksi yang ingin dicapai seorang produsen sebagai manajer adalah efisiensi ekonomi, yang bisa didekati dengan ukuran maksimasi keuntungan. Oleh karena itu istilah dari keadaan produksi optimal dan efisiensi ekonomi, merupakan istilah yang memberikan pengertian sama yang dapat dipakai berganti-ganti.

Tinggi rendahnya tingkat produktivitas kopi bubuk pada agroindustri ini, sangat ditentukan oleh besarnya produksi yang dihasilkan oleh agroindustri dari sejumlah faktor produksi yang digunakan. Semakin tinggi tingkat produktivitas kopi bubuk maka semakin efisien secara teknis/fisik agroindustri tersebut dalam menggunakan faktor produksinya. Ini menunjukan kemampuan dari 
agroindustri tersebut dalam mengalokasikan faktor produksi yang tersedia sedemikian rupa sehingga dapat menghasilkan produksi yang optimal.

Dalam penelitian ini, optimalisasi yang dimaksud adalah bagaimana upaya penggunaan faktor produksi pada agroindustri kopi bubuk secara optimal sehinggga keuntungan yang diterima agroindustri menjadi maksimum. Tingkat harga yang berfluktuasi mempengaruhi efsiensi harga dari Agroindustri kopi bubuk XYZ. Demikian juga dengan produktivitas faktor produksi yang cennderung tidak stabil akan mengganngu efisiensi teknik/ fisik dari agorindustri dalam mengalokasikan bahan baku dan tenaga kerja. Kedua efisiensi ini yaitu teknis dan harga merupakan kondisi yang mempengaruhi efisiensi ekonomis dalam penggunaan faktor produksi untuk mendapatkan produk yang optimal sehingga tercapai keuntungan maksimum yang dapat diterima oleh kopi bubuk Agroindustri XYZ.

\section{METODE PENELITIAN}

\section{Tempat dan Waktu Penelitian}

Artikel ini merupakan hasil penelitian yang dilakukan secara sengaja (purposive) dimana dilaksanakan pada Agroindustri XYZ dengan merk perusahaan kopi bubuk PD Ayam Ras, yang beralamat di Jalan Raden Wijaya RT.35 RW.08 Kecamatan Jambi Selatan Kota Jambi. Pemilihan lokasi dilakukan dengan pertimbangan bahwa Agroindustri XYZ adalah agroindustri yang mengolah biji kopi yang masih segar menjadi kopi bubuk yang siap dikonsumsi dan merupakan salah satu agroindustri pengolah kopi yang sudah lama didirikan yaitu pada Tahun 2003.

\section{Metode Penelitian}

Jenis data yang dikumpulkan dalam penelitian ini meliputi data primer dan data sekunder. Data primer dalam penelitian ini diperoleh dengan cara observasi dan wawancara langsung dari narasumber. Data sekunder merupakan data yang berkaitan dengan penelitian ini.

\section{Analisis Data}

Untuk mengetahui pengaruh penggunaaan faktor produksi biji kopi dan tenaga kerja secara kuantitatif terhadap produksi kopi bubuk dilakukan dengan analisis menggunakan model fungsi produksi Cobb Douglas yang diformulasikan pada persamaan (1).

$Y=a X_{1}^{b 1} X_{2}^{b 2}$

Untuk memudahkan pendugaan analisis maka persamaan data diubah kedalam persamaan logaritma natural sebagai berikut :

$\operatorname{Ln} Y=\operatorname{Ln} a+b_{1} \operatorname{Ln} X_{1}+b_{2} \operatorname{Ln} X_{2}$

Dimana

$Y=$ Produksi kopi bubuk ( $\mathrm{kg} / \mathrm{tahun})$

$X_{1}=$ Jumlah bahan baku yang digunakan (biji kopi/kg/tahun)

$X_{2}=$ Tenaga kerja yang digunakan (HOK/tahun)

$b_{i}=$ koefisien regresi (elastisitas produksi)

$i=1,2$

$a=$ intercept

Kondisi optimum tercapai pada saat $\mathrm{NPM}_{\mathrm{X}} / \mathrm{H}_{\mathrm{Xi}}=1$. Apabila rasio dari variabel itu kurang atau lebih besar dari satu maka penggunaan faktor produksi sudah tidak atau belum efisien (optimum) secara ekonomi. Untuk mengetahui penggunaan faktor produksi yang optimum digunakan rumus (3).

$X i=\frac{b i x Y x H y}{H x i}$

Dimana :

$X i=$ Jumlah faktor produksi yang optimum

$b i=$ Elastisitas produksi

$Y \quad=$ Jumlah produksi

$H y=$ Harga produk

$H x i=$ Harga faktor produksi.

Rumus (3) diturunkan dari kriteria yang tetap mengkondisikan penggunaan faktor produksi optimum (efisien secara ekonomi) yaitu pada saat $N P M_{X i} / H_{X i}=1$ atau $N P M_{X i}=$ $H_{X i}$. Dimana $X i$ dijadikan sebagai variabel yang akan dicari nilai optimumnya dengan memperhatikan $b i$, produk $(Y)$, harga produk (Hy) dan harga faktor produksi (Hxi) yang sudah tertentu (given).

\section{HASIL DAN PEMBAHASAN}

Profil Agroindustri PD. XYZ 
Agroindustri ini didirikan pada tahun 2003, oleh beberapa orang mantan karyawan yang pernah bekerja pada salah satu agroindustri kopi bubuk terbesar di Kota Jambi. Bentuk usaha ini merupakan Perusahaan Dagang (PD), yang dimiliki oleh satu orang pemilik dan sekaligus bertindak sebagai pimpinan. Dalam mengelola usaha kopi bubuk pemilik perusahaan dibantu oleh beberapa orang sebagai kepala bagian dan karyawan.

Bahan baku yang digunakan oleh agroindustri ini adalah biji kopi jenis arabika. Pemilihan bahan baku ini karena jenis kopi arabika memiliki kualitas buah yang lebih tinggi dibandingkan jenis kopi yang lainnya. Menurut Najyati dan Danarti (2006), kandungan air biji kopi arabika rendah yaitu $12 \%$ dan tingkat rendemen $\pm 18 \%$. Biji kopi arabika ini dibeli dari luar provinsi Jambi yaitu dari Kabupaten Curup dan Bengkulu. Pembelian bahan baku dilakukan dengan pemesanan dan diantar langsung ke kota Jambi oleh agen pemasok satu kali dalam dua minggu atau pada saat bahan baku biji kopi tinggal sedikit. Dalam mengolah biji kopi mentah menjadi kopi bubuk, agroindustri menggunakan beberapa bentuk mesin produksi. Mesin-mesin yang digunakan dalam kegiatan pengolahan biji kopi ini adalah mesin penyangraian, mesin penggiling, mesin pendingin dan mesin press.

Tenaga kerja yang digunakan agroindustri berasal dari warga masyarakat yang bertempat tinggal di sekitar pabrik. Dengan merekrut tenaga kerja yang demikian, maka kegiatan yang dilakukan agroindustri ini mendapat dukungan dari warga setempat. Tenaga kerja yang digunakan dalam kegiatan agroindustri ini merupakan tenaga kerja yang tidak memerlukan keahlian khusus, sehingga perusahaan tidak kesulitan dalam mendapatkan pekerja. Bagi tenaga kerja yang ditempatkan di bidang pemasaran, manajemen agroindustri memberikan pelatihan dengan tujuan agar tenaga kerja di bidang tersebut dapat memperkenalkan dan menjual produknya sehingga target penjualan kopi bubuk dapat tercapai.

Pemasaran kopi bubuk agroindustri ini masih berada dalam lingkup wilayah Provinsi Jambi, yaitu meliputi Kota Jambi, Kabupaten Muaro Jambi, Batanghari, Tebo, Bungo, Tanjung Jabung Timur dan Tanjung Jabung Barat. Banyaknya jenis kopi bubuk dengan berbagai merk dagang yang beredar di pasaran seperti Kopi AAA, Kopi Paman, berbagai kopi instan, merupakan kendala persaingan dalam pemasaran produk sehingga agroindustri ini belum bisa memasarkan kopi bubuk keluar dari Provinsi Jambi.

Jumlah bahan Baku, Tenaga kerja dan Produksi Kopi Bubuk Rata-rata penggunaan bahan baku biji kopi dan tenaga kerja serta produksi kopi bubuk yang dihasilkan agroindustri pada tiga tahun terakhir dapat dilihat pada Tabel 1 .

Tabel 1. Rata-rata jumlah bahan baku (biji kopi), tenaga kerja yang digunakan dan produksi kopi bubuk pada agroindustri kopi bubuk per triwulan tahun 2019

\begin{tabular}{lr}
\hline \multicolumn{1}{c}{ Uraian } & \multicolumn{1}{c}{ Jumlah } \\
\hline Bahan baku /biji kopi (kg) & $23.358,50$ \\
Tenaga kerja (HOK) & 91,00 \\
Produksi /kopi bubuk (kg) & $22.189,30$ \\
\hline
\end{tabular}

Sumber: Data Primer, 2019

Berdasarkan Tabel 1 dapat dijelaskan bahwa dalam pengolahan biji kopi menjadi kopi bubuk terjadi penyusutan berat produksi (rendemen) sebesar $5 \%$ dari jumlah bahan baku yang digunakan. Rata-rata penggunaan faktor produksi dan produksi kopi bubuk dihitung per triwulan proses produksi. Jika dihitung dalam satu bulan dengan kerja efektif 25 hari, maka jumlah bahan baku yang dipakai adalah $7.786,2 \mathrm{~kg}$ atau $311,45 \mathrm{~kg}$ per hari. Satu hari kerja pada agroindustri ini adalah 6 jam dimulai bekerja dari jam 8.00 wib sampai dengan jam 14.00 wib. Kemudian rata-rata produksi yang dihasilkan jika dihitung dalam satu bulan adalah 7.396,61 $\mathrm{kg}$ atau 295,86 kg tiap hari proses produksi.

Penggunaan tenaga kerja jika dihitung dalam jam kerja maka diperoleh sebesar 13.650 jam atau 4.550 jam perbulan. Pada setiap hari proses produksi, tenaga kerja yang digunakan sebesar 182 jam dengan rata-rata jumlah pekerja sebanyak \pm 30 orang.

Jumlah mesin pengolahan yang dipakai dalam proses produksi sebanyak 1 unit mesin yang terdiri dari mesin roasting untuk mengsangrai biji kopi, mesin penggiling dan mesin pendingin. Rata-rata bahan baku biji kopi yang diolah per hari tidak melebihi dari kapasitas mesin. Jumlah maksimum bahan baku yang diolah dengan menggunakan 1 
mesin, diketahui adalah 336,67 $\mathrm{kg} / \mathrm{hari}$ atau $25.250 \mathrm{~kg}$ per triwulan produksi.

Mengenai rata-rata penerimaan kopi bubuk Agroindustri XYZ per triwulan dapat dilihat pada Tabel 2.

Tabel 2. Rata-rata penerimaan kopi bubuk Agroindustri XYZ per triwulan tahun 2019

\begin{tabular}{lc}
\hline \multicolumn{1}{c}{ Uraian } & Jumlah \\
\hline Rata-rata Produksi $(\mathrm{Kg})$ & $22.189,30$ \\
Rata-rata Harga $(\mathrm{Rp} / \mathrm{Kg})$ & $70.000,00$ \\
Rata-rata Penerimaan $(\mathrm{Rp} / \mathrm{Kg})$ & $1.553 .251 .000,00$ \\
\hline
\end{tabular}

Sumber: Data Primer, 2019

\section{Analisis Penggunaan Faktor Produksi Optimal}

Pada penelitian ini data yang digunakan untuk menganalisis penggunaan faktor produksi bahan baku biji kopi dan tenaga kerja yang optimal, adalah data agroindustri tiga tahun terakhir. Hasil analisis regresi fungsi produksi Cobb-Douglas pada agroindustri kopi bubuk dapat dilihat pada Tabel 3.

Tabel 3. Hasil regresi penggunaan faktor produksi pada agroindustri kopi bubuk

\begin{tabular}{lcc}
\hline \multicolumn{1}{c}{ Variabel Independen } & $\begin{array}{c}\text { Koefisisen } \\
\text { Regresi }\end{array}$ & Probability \\
\hline Ln $\mathrm{X}_{1}$ & 0,409 & 0,0010 \\
Ln $\mathrm{X}_{2}$ & 0,414 & 0,0000 \\
$\mathrm{C}$ & 4,031 & 0.0002 \\
$R$-squared $\left(\mathrm{R}^{2}\right)$ & 0,986 & \\
Pob. F & 0,0000 & \\
\hline
\end{tabular}

Sumber: Analisis Data Primer, 2019

Berdasarkan Tabel 3, penggunaan bahan baku biji kopi dan tenaga kerja dalam menghasilkan kopi bubuk pada dapat diformulasikan dengan persamaan (4).

$$
\begin{aligned}
\operatorname{Ln} Y & =\operatorname{Ln} 4,031+0,409 \operatorname{Ln} X_{1}+0,414 \operatorname{Ln} X_{2} \\
Y & =56,3 X_{1}{ }^{0,409} X_{2}{ }^{0,414}
\end{aligned}
$$

Pengaruh masing-masing faktor produksi bahan baku biji kopi dan tenaga kerja terhadap produksi kopi bubuk menunjukan probabilita $<$ 0,05 , yang artinya penambahan $10 \%$ bahan baku biji kopi dan tenaga kerja secara individu berpengaruh nyata terhadap peningkatan produksi kopi bubuk sebesar masing-masing nilai koefisien regresinya, yaitu 4,09\% dari faktor produksi bahan baku dan $4,14 \%$ dari tenaga kerja.

Pada penelitian ini hasil penjumlahan koefisien regresi masing-masing penggunaan faktor produksi diperoleh $\mathrm{Ep}=0,823$ yang berarti penggunaan faktor produksi (biji kopi dan tenaga kerja) agroindustri kopi bubuk selama tiga tahun terakhir pada periode yang diteliti berada di tahap/daerah produksi yang efisien secara fisik dan memenuhi kondisi syarat atau kondisi perlu (necessary condition) dalam kajian efisiensi ekonomi. Kondisi syarat hanya dikaitkan dengan hubungan fisik dan bersifat rasional.

Tingkat efisiensi ekonomi/optimum dari penggunaan faktor produksi bahan baku biji kopi dan tenaga kerja dalam menghasilkan produksi kopi bubuk dapat dilihat pada Tabel 4.

Tabel 4 menunjukan bahwa penggunaan faktor produksi bahan baku biji kopi dan tenaga kerja pada agroindustri kopi bubuk secara ekonomi belum efisien/optimum dan mempunyai potensi untuk ditambah dalam upaya mencapai keuntungan maksimum.

Untuk menentukan berapa besar ke dua faktor produksi tersebut perlu ditambah, menggunakan rumus $N P M_{X i} / H_{X i}=1$. Angka indeks rasio $=1$ merupakan batas ukuran bahwa penggunaan faktor produksi adalah efisien.

Tabel 4. Efisiensi penggunaan bahan baku biji kopi dan tenaga kerja pada agroindustri kopi bubuk

\begin{tabular}{lcc}
\hline Komponen yang diketahui & Bahan baku biji kopi $\left(\mathrm{X}_{1}\right)$ & Tenaga kerja $\left(\mathrm{X}_{2}\right)$ \\
\hline Produksi kopi bubuk (Y) & $22.189,30 \mathrm{~kg}$ & \\
$\mathrm{H}_{\mathrm{Y}}$ & $\mathrm{Rp} 70.000 / \mathrm{kg}$ & $91 \mathrm{HOK}$ \\
Penggunaan faktor produksi & $23.358,50 \mathrm{~kg}$ & 0,414 \\
Koefisien regresi (Ep) & 0,409 & $\mathrm{Rp} \mathrm{5.625.000,00}$ \\
$\mathrm{H}_{\mathrm{Xi}} /$ satuan & $\mathrm{Rp} 22.000,00$ & 1,26 \\
$\mathrm{NPM}_{\mathrm{Xi}} / \mathrm{H}_{\mathrm{Xi}}$ & 1,24 & \\
\hline
\end{tabular}

Sumber: Analisis Data Primer, 2019 
Ulma, R. O., Nurchaini, D. S., Damayanti, Y.: Analisis Optimasi Penggunaan ...

Tabel 5. Jumlah optimal dan aktual penggunaan faktor produksi dan produksi pada agroindustri kopi bubuk

\begin{tabular}{lcccc}
\hline \multicolumn{1}{c}{ Faktor Produksi } & Optimal & Aktual & Marjin & $\%$ \\
\hline Bahan baku $\left(\mathrm{X}_{1}\right) / \mathrm{kg}$ & $28.876,35$ & $23.358,5$ & $5.517,85$ & 23,62 \\
Tenaga kerja $\left(\mathrm{X}_{2}\right) / \mathrm{HOK}$ & 114 & 91 & 23 & 25,30 \\
Produksi $(\mathrm{Y}) / \mathrm{kg}$ & $27.354,32$ & $22.189,30$ & $5.165,02$ & 23,28 \\
\hline
\end{tabular}

Sumber: Analisis Data Primer, 2019

Tabel 6. Keuntungan optimal agroindustri kopi bubuk per triwulan

\begin{tabular}{lccc}
\hline \multicolumn{1}{c}{ Uraian } & Keadaan Optimal $^{(*)}$ & Keadaan Aktual & \% Marjin \\
\hline Produksi (Kg) & $27.354,32$ & $22.189,30$ & 23,28 \\
Penerimaan (Rp) & $1.914 .802 .400,00$ & 1.553 .251 .000 & 23,28 \\
Biaya Bahan Baku (Rp) & $635.279 .700,00$ & 513.887 .000 & 23,62 \\
Biaya Tenaker (Rp) & $214.775 .000,00$ & 170.625 .000 & 34,48 \\
Total Biaya (Rp) & $850.054 .700,00$ & 684.512 .000 & 26,20 \\
Keuntungan (Rp) & $1.064 .829 .700,00$ & 868.739 .000 & 22,68 \\
\hline
\end{tabular}

Sumber: Analisis Data Primer, 2019

Dengan rumus ini, variabel bahan baku biji kopi $\left(\mathrm{X}_{1}\right)$ dan tenaga kerja $\left(\mathrm{X}_{2}\right)$ merupakan variabel yang akan dicari jumlah optimal penggunaannya $(*)$, pada harga jual produk $\left(\mathrm{H}_{\mathrm{Y}}\right)$, harga faktor produksi $\left(\mathrm{H}_{\mathrm{Xi}}\right)$ dan $\mathrm{Ep}(\mathrm{bi})$ yang tetap.

Jumlah optimal penggunaan faktor produksi bahan baku biji kopi $\left(\mathrm{X}_{1}\right)$, tenaga kerja $\left(\mathrm{X}_{2}\right)$ dan perbandinganya dengan pengunaan faktor produksi aktual yang diusahakan agroindustri kopi bubuk dapat dilihat pada Tabel 5.

Dari Tabel 5 dapat dijelaskan bahwa agar maksimisasi keuntungan per triwulan pada agroindustri kopi bubuk dapat tercapai, maka penggunaan faktor produksi bahan baku biji kopi dapat ditambah hingga jumlah optimal menjadi sebesar $28.876,35 \mathrm{~kg}$. Dalam satu bulan jumlah optimal jumlah bahan baku yang dipakai menjadi $9.625,45 \mathrm{~kg}$ atau $385,02 \mathrm{~kg}$ per hari. Penambahan bahan baku ini cukup berpotensi untuk dilakukan karena agroindustri kopi bubuk XYZ sebenarnya memiliki 3 unit mesin pengolahan kopi. Pada awal berdirinya, tahun 2003, agroindustri ini menggunakan 2 mesin, kemudian ditambah menjadi 3 mesin. Namun karena adanya persaingan pasar dengan kopi bubuk dari perusahaan lain dan bermacam-macam jenis kopi instan, maka pada tahun 2013 sampai sekarang agroindustri kopi bubuk XYZ mengurangi jumlah produksinya dengan hanya menggunakan satu unit mesin pengolahan.

Sedangkan penggunaan tenaga kerja dapat ditambah hingga jumlah optimal menjadi sebesar 114 orang. Apabila dihitung dalam jam kerja maka jumlah optimal penggunaan jam kerja menjadi 17.100 jam kerja atau 5.700 jam kerja per bulan. Dalam satu hari kerja batas penggunaan optimal kerja menjadi 228 jam dengan jumlah pekerja menjadi \pm 38 orang. Karena melebihi penggunaan batas optimal, penggunaan tenaga kerja dan bahan baku biji kopi menjadi tidak efisien $\left(\mathrm{NPM}_{\mathrm{Xi}}<\mathrm{H}_{\mathrm{Xi}}\right)$

Keuntungan optimal yang dapat diterima agroindustri kopi bubuk PD XYZ disajikan pada Tabel 6. Penggunaan bahan baku dan tenaga kerja yang optimal akan meningkatkan biaya dari kedua faktor produksi tersebut. Akan tetapi produksi dan penerimaan agroindustri juga meningkat. Sehingga dengan pengunaan kerja dan bahan baku yang optimal keuntungan yang dapat diterima agroindustri kopi bubuk XYZ meningkat sebesar $22,68 \%$ dari keuntungan aktual yang diterima agoindustri tersebut.

\section{KESIMPULAN}

Berdasarkan hasil uji statistik, secara fisik/tehnis penambahan bahan baku biji kopi dan tenaga kerja berpengaruh terhadap kenaikan produksi kopi bubuk. Setiap penambahan bahan baku biji kopi sebesar $10 \%$ maka akan meningkatkan produksi kopi bubuk sebesar 4,09\%, sedangkan penambahan tenaga kerja $10 \%$ akan meningkatkan produksi kopi bubuk sebesar $4,14 \%$.

Penggunaan faktor produksi bahan baku biji kopi dan tenaga belum mencapai efisiensi ekonomi. Hal ini memberikan indikasi bahwa penggunaan bahan baku dan tenaga kerja pada 
agroindustri berpotensi untuk ditambah guna mendapatkan produk kopi bubuk yang optimal yang bisa memberikan keuntungan maksimum.

Penggunaan faktor produksi bahan baku biji kopi per triwulan dapat ditambah hingga jumlah optimal menjadi sebesar 28.876,35 $\mathrm{kg} /$ triwulan atau terdapat kenaikan 23,62 \% dari penggunaan aktual. Dalam satu bulan atau satu hari produksi jumlah optimal jumlah bahan baku yang dipakai adalah $9.625,45 \mathrm{~kg}$ atau $385,02 \mathrm{~kg}$. Sedangkan penggunaan tenaga kerja dapat ditambah hingga jumlah optimal sebesar 114 hari orang kerja (HOK) atau terjadi penambahan $25,30 \%$ dari penggunaan tenaga kerja aktual. Dihitung dalam jam kerja maka jumlah optimal penggunaan jam kerja menjadi 17.100 jam kerja per triwulan atau 5.700 jam kerja per bulan. Dalam satu hari kerja batas penggunaan optimal kerja menjadi 228 jam dengan jumlah pekerja menjadi \pm 38 orang. Jumlah produksi optimum adalah 27.354,32 $\mathrm{kg} /$ triwulan, meningkat sebesar $5.165,02 \mathrm{~kg}$ $(23,28 \%)$ dari produksi aktual.

Dalam proses produksi selanjutnya diharapkan agroindustri bisa menambah bahan baku dan tenaga kerja agar menghasilkan produk kopi bubuk yang memberikan keuntungan yang lebih baik lagi. Pengusaha diharapkan tetap terus termotivasi untuk mengembangkan usahanya melalui peningkatan kualitas hasil yang sesuai dengan selera konsumen atau permintaan pasar. Untuk mendukung berlangsungnya pengembangan usaha ini maka dibutuhkan dukungan dari berbagai pihak yang terkait baik pemerintah maupun swasta.

\section{DAFTAR PUSTAKA}

Andrianto, T. T. (2014). Pengantar Ilmu Pertanian. Yogyakarta: Global Pustaka Utama.

Doll, P. J., \& Orazem, F. (1978). Production Economics, Theory with and Applications. USA: JhonWiley \& Son, Inc.

Hasan, I. (2004). Analisis Data Penelitian dengan Statistik. Jakarta: Bumi Akasara.
International Coffee Organization. (2014). ICO Annual Review 2010-2013. London: International Coffee Organization.

Mizfar, F., \& Sinaga, A. (2015). Analisis faktor-faktor yang mempengaruhi perilaku konsumen dalam pengambilan keputusan pembelian kopi instan. SEPA(Jurnal Sosial Ekonomi Pertanian Dan Agribisnis), 11(2), 175 - 180.

Najiyati, S., \& Danarti. (2006). Kopi Budidaya dan Penanganan Lepas Panen. Jakarta: Penebar Swadaya.

Soekartawi. (1989). Prinsip Dasar Ekonomi Pertanian, Teori dan Aplikasi. Jakarata: Rajawali Press.

Soekartawi. (1994). Teori Ekonomi Produksi dengan Pokok Bahasan Analisis Fungsi Cobb Douglas. Jakarta: Raja Grafinso Persada.

Soekartawi. Analisis Usahatani. (1995). Jakarta: UI Press.

Soekartawi. Pengantar Agroindustri. (2001). Jakarta: Raja Grafindo Persada.

Supriyadi. (2017). Analisis product life cycle produk kopi bubuk di Kota Jambi [Skripsi]. Fakultas Pertanian Universitas Jambi, Jambi. 